\title{
Amplification of Antipollution Action of JP8 using a Bioorganic Compound
}

\author{
C.G. Tsanaktsidis, S.G. Christidis and G.T. Tzilantonis
}

\begin{abstract}
In this paper we try to investigate how a bioorganic compound influences the physicochemical properties of jet fuel (JP8). Using specific volume of JP8(F-34) and specific mass of the hydrophilic polymer, we determine density, kinematic viscosity $-\mathbf{2 0}^{\circ} \mathrm{C}$, humidity, total acid number, heat of combustion, distillation residue, distillation temperature $10 \%$ recovered and flash point in order to study the effect of the bioorganic compound. The results show that humidity, total acid number could decrease considerably and heat of combustion, flash point could increase significantly, so that jet fuel's quality is improving.
\end{abstract}

Index Terms-Bioorganic Compound, Distillation Proces, JP8, Physicochemical Properties, Total Acid Number (TAN).

\section{INTRODUCTION}

JP-8 is a kerosene-based fuel that is blended with specific additives to make it suitable for use in military applications. Although, initially, it was used as an aviation fuel, its applications have been expanded to include ground vehicles as well as all types of diesel engine-powered systems and furnaces [4]. This is because both the U.S. and the NATO military forces have decided to simplify their fuel transport and distribution operations through the use of a single fuel [1]. JP-8 is approximately $99.8 \%$ kerosene by weight $[1,2]$ and is a complex mixture of higher-order hydrocarbons, including alkanes, cyclo-alkanes, and aromatic molecules. JP-8 contains three mandatory additives: a fuel system icing inhibitor, a corrosion inhibitor, and a static dissipater additive [3].

In this paper, specific laboratory exercises for the analysis of jet fuel properties are presented, which concern the determination of density, kinematic viscocity $\left(-20^{\circ} \mathrm{C}\right)$, humidity, total acid number, heat of combustion, distillation temperature $90 \%$ recovered.

However, two of the most important factors during the

Manuscript received January 24, 2011.

C.G. Tsanaktsidis is with Laboratory of Qualitative Fuel Control, Department of Pollution Control and Technologies, Technological Education Institute of Western Macedonia, Kila, Kozani -Greece 50100 (corresponding author to provide phone: +302461068034; e-mail: tsanaktsidis@teikoz.gr).

S.G. Christidis is with Laboratory of Qualitative Fuel Control, Department of Pollution Control and Technologies, Technological Education Institute of

Western Macedonia, Kila, Kozani -Greece 50100 (e-mail: christidis.chem@hotmail.com).

G.T. Tzilantonis is with Laboratory of Qualitative Fuel Control, Department of Pollution Control and Technologies Technological Education Institute of Western Macedonia, Kila, Kozani -Greece 50100 (e-mail: georgekoz03@gmail.com). combustion of JP8 are humidity and total acid number (TAN). Humidity because it causes corrosion, can cause ice blockage in the power grid that can be formed in low temperatures and last it can be divided during the warming-up and cause flame extinguishing from the produced steam (water vapour) and total acid number, because is an indication of the degree of oxidation and it is a facile method for monitoring fuel quality.

Our effort focuses on, how the conformation of the hydrophilic polymer via charged groups and dynamic absorption of water molecules (because we expect the polymer to retain these molecules) [5], acts on the physicochemical properties of JP8 which have significant role in qualitative control of jet fuels and their behavior during combustion. For this aim we introduce in a sample of JP8 the hydrophilic polymer Thermal Polyaspartate Anion TPA for forty five (45) minutes [5]. It is stressed that the volume of JP8 and the mass of the polymer maintain stable.

\section{PRODUCTION, CHARACTERISTICS AND SPECIFICATIONS OF JP8}

\section{A. Production and Characteristics of JP8.}

Light jet fuels such as jet fuel no.1 (kerosene) are refined from straight distillation of crude oil or distillation of crude oil in the presence of a catalyst. Fuels such as JP-8 are then chemically enhanced with antioxidants, dispersants, or corrosion inhibitors to meet the requirements for a specific application. It consists of a mixture of petroleum hydrocarbons, chiefly of the methane series, which typically have from 10 to 16 carbon atoms per molecule. The typical components of the end product of jet fuel include paraffins (n-, iso-, monocycle-, bicycle- and tricycle-), olefins, aromatics and nitrogen and sulfur impurities [14].

\section{B. Specifications of JP8.}

Jet fuels are produced from refined crude petroleum to meet specifications for particular uses.

In the Table I below specifications of US Air Force for JP8-F34 (MIL-DTL-83133E 1 April 1999) are presented.

\section{EXPERIMENTAL PROCESS}

\section{A. Determination of physicochemical properties of JP8.}

At first the values of physicochemical properties of JP8 (F34) (using an amount of $1000 \mathrm{~mL}$ ) are determined with the 
ASTM methods and the appropriate equipment.

Although there are many standard methods used for analyzing the various properties, emphasis is placed on methods determined in our laboratory. The results are presented in the Table II below.

TABLE I SPECIFICATIONS OF PHYSICOCHEMICAL PROPERTIES AND THEIR METHODS OF DETERMINATION OF JP8 (US AIR FORCE

\begin{tabular}{ccc} 
MIL-DTL-83133E 1 APRIL 1999) ${ }^{[15]} \cdot$ \\
\hline \hline Physicochemical Property & JP8 & $\begin{array}{c}\text { Methods of } \\
\text { Determination }\end{array}$ \\
\hline Density $15^{\circ} \mathrm{C}, \mathrm{g} / \mathrm{mL}$ & $0.775-$ & ASTM \\
Kinematic Viscosity, $\left(-20^{\circ} \mathrm{C}\right)$ & 0.840 & $\mathrm{D} 1298^{[8]}$ \\
$\mathrm{mm}^{2} / \mathrm{s}(\mathrm{cSt})$ & $<8.00$ & $\mathrm{D} 445^{[9]}$ \\
$\begin{array}{c}\text { Humidity } \mathrm{mg} / \mathrm{kg} \\
\text { Total Acid Number }(\mathrm{mg} / \mathrm{g} \mathrm{KOH})\end{array}$ & $<0.015$ & $\mathrm{D} 1744^{[6]}$ \\
Heat of Combustion, $\mathrm{MJ} / \mathrm{Kg}$ & $>42.8$ & $\mathrm{D} 664^{[11]}$ \\
Flash Point $\left({ }^{\circ} \mathrm{C}\right)$ & $>38$ & $\mathrm{D} 4809^{[10]}$ \\
Distillation Residue $(\mathrm{vol} \%)$ & $<1.5$ & $\mathrm{D} 93^{[13]}$ \\
Distillation Temperature $10 \%$ & & $\mathrm{D} 86^{[12]}$ \\
Recovery $\left({ }^{\circ} \mathrm{C}\right)$ & $<205$ & $\mathrm{D} 86^{[12]}$ \\
\hline \hline
\end{tabular}

TABLE II: VALUES OF PHYSICOCHEMICAL PROPERTIES OF JP8 AND ITS METHODS OF DETERMINATION.

\begin{tabular}{|c|c|c|}
\hline Physicochemical Property & $\begin{array}{c}\text { JP8 } \\
(\mathrm{F} 34)\end{array}$ & $\begin{array}{c}\text { Methods of } \\
\text { Determination } \\
\text { ASTM }\end{array}$ \\
\hline Density $15^{\circ} \mathrm{C}, \mathrm{g} / \mathrm{mL}$ & 0.797 & D $1298^{[8]}$ \\
\hline $\begin{array}{c}\text { Kinematic Viscosity, }\left(-20^{\circ} \mathrm{C}\right) \\
\mathrm{mm}^{2} / \mathrm{s}(\mathrm{cSt})\end{array}$ & 2.79 & D $445^{[9]}$ \\
\hline Humidity mg/kg & 57.1 & D $1744^{[6]}$ \\
\hline Total Acid Number (mg/g KOH) & 0.014 & D $664^{[11]}$ \\
\hline Heat of Combustion, $\mathrm{MJ} / \mathrm{Kg}$ & 43.52 & D $4809^{[10]}$ \\
\hline Flash Point $\left({ }^{\circ} \mathrm{C}\right)$ & 46 & D $93^{[13]}$ \\
\hline Distillation Residue (vol \%) & 0.005 & $\mathrm{D} 86^{[12]}$ \\
\hline $\begin{array}{l}\text { Distillation Temperature } 10 \% \\
\text { Recovery }\left({ }^{\circ} \mathrm{C}\right)\end{array}$ & 180 & D $86^{[12]}$ \\
\hline
\end{tabular}

The results of the distillation experiment it is shown in the Table III and the Fig. 1 below.

TABLE III: DISTILLATION OF JP8 (F34) ${ }^{[12]}$.

\begin{tabular}{ccc}
\hline \hline & & \\
Distillation of JP8 $(\mathrm{F} 34)$ & $($ Volume $50 \mathrm{~mL})$ & \\
\hline Distillation Volume \% Recovered & Volume & Temperature $\left({ }^{\circ} \mathrm{C}\right)$ \\
Initial Boiling Point & $(\mathrm{mL})$ & 155 \\
10 & 0 & 180 \\
20 & 5 & 190 \\
30 & 10 & 198 \\
40 & 15 & 202 \\
50 & 20 & 207 \\
60 & 25 & 210 \\
70 & 30 & 215 \\
80 & 35 & 221 \\
90 & 40 & 230 \\
95 & 45 & 238 \\
\hline \hline
\end{tabular}

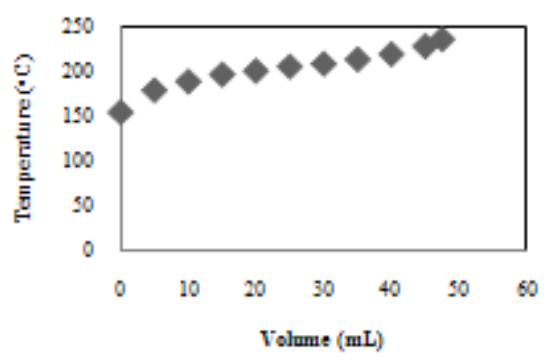

Fig. 1. Curve of Distillation of JP8 (F34) ${ }^{[12]}$.

\section{B. Determination of physicochemical properties of JP8 with TPA.}

Since polymer TPA (Fig. 2) has been prepared in a quality of $5 \mathrm{~g}$ we introduced this amount in a sample of the same jet fuel (as above) of a volume $1000 \mathrm{~mL}(1 \mathrm{~L})(5 \mathrm{~g}$ of polymer is defined from the limits of chemical additives in liquid fuels which is $1-4 \mathrm{Kg} / \mathrm{tn}$ ). This sample stays in an environment temperature for 45 minutes and we observe that the polymer remains indissoluble [5].

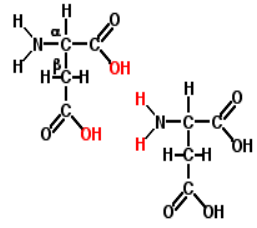

Aspatic Acid

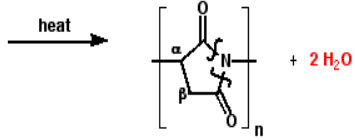

$\mathrm{NaOH}$

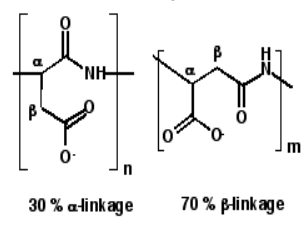

Polyaspartate

Fig. 2. Synthesis of Hydrophilic Polymer, Thermal Polyaspartate Anion (TPA). ${ }^{[5]}$.

Next, we filtrate the mixture via the method ASTM D-2276 [7] by using the filtration device Millipore. We determine the same physicochemical properties (using the ASTM methods) and the results are presented in below Table IV.

TABLE IV: VALUES OF PHYSICOCHEMICAL PROPERTIES AND THEIR METHODS OF DETERMINATION OF JP8.

\begin{tabular}{|c|c|c|}
\hline Physicochemical Property & $\begin{array}{c}\text { JP8 } \\
(\mathrm{F} 34)\end{array}$ & $\begin{array}{c}\text { Methods of } \\
\text { Determination } \\
\text { ASTM }\end{array}$ \\
\hline Density $15^{\circ} \mathrm{C}, \mathrm{g} / \mathrm{mL}$ & 0.795 & D $1298^{[8]}$ \\
\hline $\begin{array}{c}\text { Kinematic Viscosity, }\left(-20^{\circ} \mathrm{C}\right) \\
\mathrm{mm}^{2} / \mathrm{s}(\mathrm{cSt})\end{array}$ & 2.74 & D $445^{[9]}$ \\
\hline Humidity mg/kg & 42.4 & D $1744^{[6]}$ \\
\hline Total Acid Number (mg/g KOH) & 0.004 & D $664^{[11]}$ \\
\hline Heat of Combustion, $\mathrm{MJ} / \mathrm{Kg}$ & 44.56 & D $4809^{[10]}$ \\
\hline Flash Point $\left({ }^{\circ} \mathrm{C}\right)$ & 49 & D $93^{[13]}$ \\
\hline Distillation Residue (vol \%) & 0.005 & $\mathrm{D} 86^{[12]}$ \\
\hline $\begin{array}{c}\text { Distillation Temperature } 10 \% \\
\text { Recovery }\left({ }^{\circ} \mathrm{C}\right)\end{array}$ & 182 & D $86^{[12]}$ \\
\hline
\end{tabular}

The results of the distillation experiment it is shown in the Table V and the Fig. 3 below. 
TABLE V: DistiLlation OF JP8 (F34) WiTH TPA ${ }^{[12]}$.

Distillation of JP8 (F34) with TPA (Volume $50 \mathrm{~mL}$ of JP8)

\begin{tabular}{ccc}
\hline Distillation Volume \% Recovered & $\begin{array}{c}\text { Volume } \\
(\mathrm{mL})\end{array}$ & Temperature $\left({ }^{\circ} \mathrm{C}\right)$ \\
Initial Boiling Point & 0 & 158 \\
10 & 5 & 182 \\
20 & 10 & 193 \\
30 & 15 & 198 \\
40 & 20 & 203 \\
50 & 25 & 207 \\
60 & 30 & 211 \\
70 & 35 & 215 \\
80 & 40 & 221 \\
90 & 45 & 229 \\
95 & 47.5 & 239 \\
\hline \hline
\end{tabular}

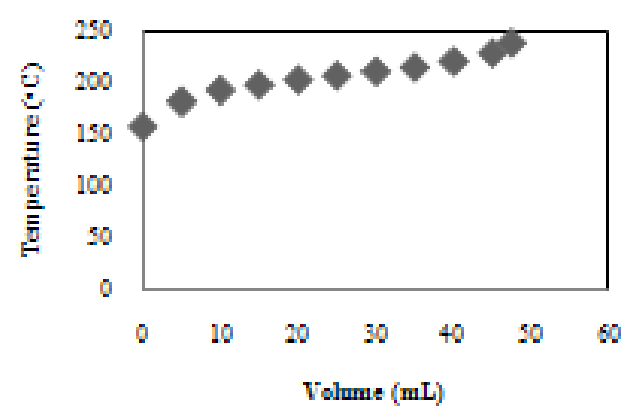

Fig. 3. Curve of Distillation of JP8 (F34) with TPA ${ }^{[12]}$.

\section{CONCLUSIONS}

According to the values of the physicochemical properties we realize that the sample of JP8 (F34), as well as the sample of JP8 with TPA met the US Air Force specifications (Tables I, II and IV) (MIL-DTL-83133E 1 April 1999).

Firstly, comparing values of physicochemical properties of density, kinematic viscosity $(-20 \mathrm{oC})$, distillation residue and distillation temperature of $10 \%$ recovery (Tables II-IV) we realize that they are not influenced by the use of the polymer.

Secondly, the values of Tables II -IV have shown, that JP8 with TPA, have less water and lower total acid number (TAN) than the other sample with simple JP8 (about $26 \%$ and $71 \%$ equivalently). The result of elimination of humidity and the low TAN, may not only effect in several functions (reduce icing effect- no use of anti-icing additives), but also could avert corrosion during storage.

Thirdly, the increased values of the heat of combustion and the flash point (Tables II and IV) could upgrade the thermal efficiency of producing power, improve ignition quality and reduce knock and smoke.

Furthermore, TPA could be used during the transportation of JP8 into the airports or in the storage tanks in order to eliminate humidity in short time before fuels use.

In conclusion, the values of the physicochemical properties from JP8 with TPA, amplifies its antipollution action, because no anti icing additives or chemicals for reducing acidity are needed so that the exhaust gases are less polluting to the environment.

\section{REFERENCES}

[1] JP-8, the Single Fuel Forward, an Information Compendium. U.S Army Tank Automotive and Armaments Command, Warren, MI,May 2001.

[2] Aviation Fuels Technical Review (FTR-3), Chevron Products Company, 2000.

[3] Annual Energy Outlook 2002 with Projections to 2020. U.S. Department of Energy and National Energy Information Center, DOE/EIA 0383, December 2001.

[4] Constantinos D. Rakopoulos, Dimitrios T. Hountalas, Dimitrios C. Rakopoulos and Yiannis A. Levendis "Comparative Environmental Evaluation of JP-8 and Diesel Fuels Burned in Direct Injection (DI) or Indirect Injection (IDI) Diesel Engines and in a Laboratory Furnace" Energy \& Fuels, Vol. 18, No. 5 pp1302 -1308, 2004.

[5] C.G. Tsanaktsidis, S.G. Christidis and G.T. Tzilantonis, "Study about Effect of Processed Biodiesel in Physicochemical Properties of Mixtures with Diesel Fuel in order to Increase their Antifouling Action", International Journal of Environmental Science and

Development, Vol. 1, No. 2, pp 206, 2010.

[6] Determination of Water in Petroleum Products by Karl Fischer Reagent ASTM D1744-92 Standard Test Method, Withdrawn 2000.

[7] Particulate Contaminant in Aviaton Fuel by Line Sampling, ASTM D2276 - 06 Standard Test Method, 2006.

[8] Density Relative Density (Specific Gravity), or API Gravity of Crude Petroleum and Liquid Petroleum Products by Hydrometer Method, ASTM D1298 - 99 Standard Test Method, 2005.

[9] Kinematic Viscosity of Transparent and Opaque Liquids (and Calculation of Dynamic Viscosity), ASTM D445-06 Standard Test Method, 2006.

[10] Heat of Combustion of Liquid Hydrocarbon Fuels by Bomb Calorimeter (Precision Method), ASTM D4809 - 09a Standard Test Method, 2009.

[11] Acid Number of Petroleum Products by Potentiometric Titration, ASTM D664-09 $\alpha$ Standard Test Method, 2009

[12] Distillation of Petroleum Products at Atmospheric Pressure. ASTM D86 - 10a Standard Test Method, 2010.

[13] Flash Point by Pensky-Martens Closed Cup Tester, ASTM D93 - 10a Standard Test Methods, 2010.

[14] http:// www.atsdr.cdc.gov/.../tp76-c4.pdf

[15] http://propellants.ksc.nasa.gov/commodities/specs MIL_DTL_83133E.pdf

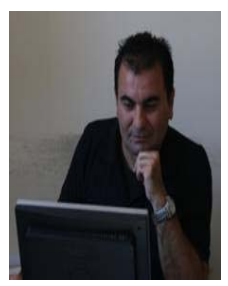

Dr. Tsanaktsidis Constantinos was born in Akrini, Kozani, Greece in 1967. In 1985 he graduated from high school (grade excellent) and in 1990 he received a Bachelor degree in Chemistry with grade 549/59. In 2004 he received his PhD from the Department of Chemistry, Faculty of Sciences, University of Ioannina with distinction "Excellent"(Thesis "Study degree of hydration, and conformational and dynamic properties of bio-organic compounds using eteronuclear NMR 14N and 31P") and started his Postdoctoral studies at the University of Ioannina, Faculty of Sciences, Department of Biological Applications and Technologies, with the object "Topics of Moisturizing amino acids and nucleic acids and structural aspects of studies of biologically active substances".

$\mathrm{He}$ is an Assistant Professor of the Department of Antipollution Control Technologies, in Technological Institute of Western Macedonia, since 1st November 2005. His areas of scientific interest are focused on: Study of Bioorganic associations' antipollution action in areas such as Conventional Fuels, Detergents, Liquid Hospital Waste.

Assistant Prof. Tsanaktsidis has participated in one (1) EU and twelve (12) national projects and has published more than twenty $(20)$ papers in referred journals and conferences.

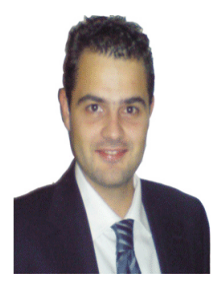

Mr Christidis Stavros was born in Ptolemaida, Greece in 1978. In 1996 he graduated from high school (grade excellent) and in 2003 he received a Bachelor degree in Chemistry, Aristotle University of Thessaloniki with grade 659. In 2005 he received his MSc from the Department of Chemistry, Faculty of Sciences, Aristotle University of Thessaloniki with distinction "Excellent".

(Thesis "Software development simulation experiments and lesson plans in the section of thermochemistry") and in 
2009 he started his PhD studies at the University of Western Macedonia, Polytechnic School, Department of Mechanical Engineering, with the object "Combined activity of fuel cells and anaerobic digestion of bio-disintergrational wastes for the renewable tri-production of energy, heat and fertilizers".

He works as a supervisor of chemical laboratory and as a technical quality assistant in an analytical chemical laboratory, according to the International Standard ISO 17025 and as a laboratorial cooperator at the Department of Antipollution Control Technologies in Technological Educational Institution of Western Macedonia the last four (4) years. His areas of scientific interest are focused on: Study of Bioorganic associations' antipollution action in areas such as Conventional fuels, non Conventional Fuels, Fuell Cells, Anaerobic Digestion, Potable Water.

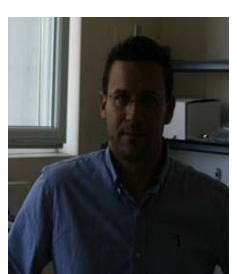

Mr Tzilantonis George was born in Zurich, Switzerland in 1972. In 2000 he received a Bachelor degree in Mechanical Engineering from the Technological Education Institute of Western Macedonia. He participated in the seminar "Education of Educators", in Technological Education Institute of Western Macedonia (14/12/2009).

$\mathrm{He}$ works as a laboratorial cooperator at the Department of Antipollution Control Technologies in Technological Educational Institution of Western Macedonia the last four (4) years and as an external cooperator of the Centre of Technological Research of Western Macedonia. He has great experience in the use and repair of the laboratorial instruments. His areas of scientific interest are focused on: Study of Bioorganic associations' antipollution action in areas such as Conventional Fuels, Detergents, Liquid Hospital Waste.

Mr Tzilantonis has published more than three (3) papers in referred journals and conferences. 